\title{
Cadmium in Cacao: 'From Soil to Bar' the Journey of Cadmium at a Farm Level
}

\section{Daniel Bravo ( $\square$ dbravo@agrosavia.co)}

Colombian Corporation for Agricultural Research

Margareth Santander

Colombian Corporation for Agricultural Research

Jader Rodríguez

Colombian Corporation for Agricultural Research

Sebastian Escobar

Colombian Corporation for Agricultural Research

\section{Research Article}

Keywords: Cadmium, cocoa, soil, post-harvesting, chocolate, single origin

Posted Date: February 15th, 2021

DOI: https://doi.org/10.21203/rs.3.rs-199662/v1

License: (c) (1) This work is licensed under a Creative Commons Attribution 4.0 International License. Read Full License 


\section{Abstract}

Cadmium (Cd) is a non-nutritive element present across the earth. In cacao crops from South America, Cd has become one of the biggest challenges due to its flux from soils, and due to the enriched content of this metal, it makes its way into the beans and finally affects the chocolate quality. This manuscript aims to show how the flux of Cd occurs, from the soil to the post-harvest phase and chocolate production, by analysing the possible inputs to the system in a single farm assessed as a model for enriched-Cd status. This study shows that both geogenic and anthropogenic activities have an incidence on the final Cd content in chocolate, especially with respect to soil properties, fertiliser applications, post-harvest treatments and chocolate production.

\section{Introduction}

Cacao is the second most important crop with significant economic and social relevance in Colombia. National production generates 60000 tons on average, and is cultivated over 176050 hectares ${ }^{1}$. While cultivated in several regions, the district of Santander is subject to special attention since this district represents $26 \%$ of the national production. However, one of the biggest challenges in exporting cacao is the presence of cadmium (Cd) in cacao beans at specific spots in farms located in Santander.

As described in the Codex Alimentarius ${ }^{2,3}$ the levels set by the EU regulation are similar to those being proposed for inclusion in Codex of 0.8 $\mathrm{mg} / \mathrm{kg}$ for chocolate with $\geq 50 \%$ to $\leq 70 \%$ cocoa solids, and $0.9 \mathrm{mg} / \mathrm{kg}$ for chocolate with $>70 \%$ cocoa solids. The categories and limits for products with $<50 \%$ total cocoa solids and for cocoa powder (100\% total cocoa solids) have yet to be defined.

The European Union has been a pioneer in legislating Cd content in foods because several of its member countries have reported an annual per capita consumption of chocolate greater than $5.5 \mathrm{~kg}{ }^{4}$. Therefore, it is necessary to reduce the risks of food safety that can be incurred due to the presence of heavy metals in the product. Meanwhile, in Colombia, there is still no clear national legislative framework regarding the maximum permissible levels of $\mathrm{Cd}$ in either soils or chocolate and cocoa derivatives. To help understand the issue, it is important to monitor and regulate the metal content in the entire cacao system to ensure products remain below established thresholds, and thus improve the competitiveness of the Colombian cacao for export, and also protecting public health and establishing a national quality control for trade based on cocoa safety. To understand $\mathrm{Cd}$ fluxes, it is useful to analyse the behaviour of metal migration from the soil to chocolate. The following sections are a journey from soil to chocolate production within a single farm.

\section{Subsoil and topsoil Cd distribution}

Very few studies have focused on assessing both the soil agronomic and post-harvest factors affecting Cd content in cacao in terms looking at the entire process in a single farm. Relevant factors include i. Cd subsoil distribution, ii. soil pH, soil organic matter (SOM), phosphorus content, iii. the application of chemical P-based fertilisers and iv. post-harvest treatments ${ }^{5-7}$.

All of these factors might have an effect on final Cd content in chocolate. Due to the fact that the distribution of Cd in soils tends to be highly heterogeneous, assessing the distribution of both soil and post-harvest Cd contents requires the use of multi-method approaches, involving an assessment of the physical, chemical and microbiological properties of the cocoa crop system. To assess heavy metal soil distribution, the twodimensional electrical resistivity tomography technique (2D-ERT) is an accurate tool for use in analysing crop systems based on previous reports 8 , and it recently used for assessing $\mathrm{Cd}$ content in cacao soils in Colombia ${ }^{9}$. This technique has been used in the assessment of soils where clay minerals and the weathering of granite rock were noticed on the ground surface ${ }^{10}$. This approach can help in identifying areas potentially high in Cd spots to aid in soil sampling to quantify $\mathrm{Cd}$ in the soil.

\section{pH, Soil Organic Matter (SOM) and phosphorus content in soil}

The variability of Cd concentrations in cocoa beans from different sites has been attributed to the 'total' soil Cd content and critical soil factors influencing $\mathrm{Cd}$ phytoavailability, such as $\mathrm{pH}$, texture and $\mathrm{SOM}^{11}$. Despite the importance of identifying the factors that govern $\mathrm{Cd}$ accumulation in cocoa beans and the need to find options to reduce its concentration, only a few studies have investigated the effects of soil and other environmental factors on heavy metal uptake by cacao plants, especially under field conditions ${ }^{12,13}$. Several studies have determined that, among the diverse soil parameters, $\mathrm{pH}$ is the most relevant for controlling plant-available $\mathrm{Cd}^{14}$. However, other critical soil parameters, such as the presence of clay, organic matter content, texture, and iron or aluminium oxide levels have also been indicated as useful properties that can help to predict Cd uptake by plants ${ }^{15}$.

Soil $\mathrm{pH}$ has also been associated with $\mathrm{Cd}$ availability in soil ${ }^{14}$, and this is particularly evident in the case of cacao crops ${ }^{5,16,17}$. There is evidence that acidic soils are associated with the presence of $\mathrm{Cd}$ and lead in plants ${ }^{16,18}$. Interestingly, acidic soils from the Santander district of Colombia have also exhibited SOM contents close to $85 \%{ }^{5}$. Furthermore, it has been observed that when zinc contents were high (average values of $11.6 \pm$ $0.2 \mathrm{mg} / \mathrm{kg}$ ) in farms located in Santander, there was an increase of available $\mathrm{Cd}^{5}$. Therefore, these physical parameters should be considered when studying $\mathrm{Cd}$ in soils and its potential accumulation in cocoa beans. 
The soil parameters above represent a picture of the complexity of soil management in the case of cacao crops. Nevertheless, in addition to these factors, fertiliser application can influence Cd phytoavailability when contaminated with this heavy metal. Regular fertiliser application could also be a key factor in bioavailability, acting as a long-term anthropogenic source of contamination and affecting both soil pH and ionic ligand interactions ${ }^{14}$ with the biota in the soil solution. Hence, fertilisation, mainly in P-like and NPK-like forms, might influence Cd speciation and complexation, thus increasing the mobility of the available $\mathrm{Cd}$ from the soils into the cacao roots.

\section{Cocoa in the post-harvest phase}

The type of post-harvest transformation of cocoa from seeds (fresh material removed from the pods) to beans (fermented and dried cocoa) along with the transformation of beans into nibs significantly influences the quality of the final product such as chocolate. This is due to the biochemical reactions involved due to the mass and heat transfer phenomena occurring inside the seeds during fermentation as well as the effects of drying and roasting ${ }^{19}$. It is possible to describe the seeds' transformation into chocolate in terms of two main steps:

From seeds to beans: During seed fermentation, the temperature rises from 28 to $50^{\circ} \mathrm{C}$, and the pH drops from 6.5 to 4.5 units. Interestingly, this is due to the microbial succession of yeasts and bacteria during the fermentation of the cocoa beans ${ }^{20}$, where yeasts, lactic acid and acetic acid bacteria are the main populations interacting in diauxic metabolic ratios. During this process, $40 \%$ of seed weight is lost to evaporation due to the liquefaction of the seed mucilage. Another $30 \%$ of weight is lost through drying ${ }^{21}$.

From beans to chocolate: During roasting, the beans are processed at temperatures ranging between 110 to $160^{\circ} \mathrm{C}$ and a time duration between 5 to 120 minutes ${ }^{22}$.

Despite the importance of the post-harvest and processing stages with respect to cocoa quality, there has been little research ${ }^{23}$ assessing how artisanal, non-technified post-harvest operations, might reduce the bean' Cd content. Some studies have noted Cd decreases comparing fresh whole seeds and fermented dried testa ${ }^{21}$, as well as derived products such as cocoa powder and chocolate; in such cases, a relationship has been established between $\mathrm{Cd}$ content, single-origin cacao and genotypes $7,21,24-26$. The findings from a previous study 21 indicate that there is a higher Cd content in the testa $(1.83 \mathrm{mg} / \mathrm{kg}$ on average) than in the cotyledon ( $0.88 \mathrm{mg} / \mathrm{kg}$ on average), with considerable variation in the genetic material

21. This final aspect in the post-harvest operation influences the Cd values of chocolate within the range of $0.004-3.15 \mathrm{mg} / \mathrm{kg} 24$.

Therefore, the aim of this study was to analyse the Cd flux using cacao from a single farm by considering the influence of i. soil parameters, ii. fertiliser amendments and iii. post-harvest operating processes. The study describes the movement of Cd from soil to beans to fermented beans to chocolate, in a single process.

\section{Results}

\subsection{Soil cadmium content and distribution}

The farm was located in the municipality of San Vicente de Chucurí in Santander, a cacao producing district of Colombia. The farm was found to have a high pseudo-total soil Cd content $(3.50 \mathrm{mg} / \mathrm{kg})$. Regarding pseudo-total soil Cd per soil boundary, according to the resistivities found at the same pit profiles, higher values were found at boundaries $A$ (ranging in soil depth from $0-20 \mathrm{~cm}$ ) and $B$ (ranging in soil depth from $21-72 \mathrm{~cm}$ ), with average $\mathrm{Cd}$ values of $1.37 \pm 0.4$ and $2.38 \pm 0.3 \mathrm{mg} / \mathrm{kg}$, respectively. According to the $2 \mathrm{D}$-ERT technique (Fig. $1 \mathrm{a}$ ), the resistivities ranging from 950-1000 $\Omega \times \mathrm{m}$ were related to $\mathrm{Cd}$ content at the same boundaries. Therefore, the $A$ and $B$ boundaries were more related to $\mathrm{Cd}$ content in the soil profiles in that farm rather than other boundaries. Other farms from the municipality of El Carmen de Chucurí, allocation area dedicated to cacao production near to the assessed farm, have shown similar patterns of subsoil Cd distribution at the $A$ and $B$ boundaries, with average Cd values of $1.92 \pm 1$ and $3.24 \pm 0.5 \mathrm{mg} / \mathrm{kg}$, respectively.

The apparent resistivity ranging from 900-1270 $\Omega \times$ m was related to a high concentration of rock geomorphs at the $C$ bottom boundary (ranging from $75-100 \mathrm{~cm}$ in soil depth). For instance, a resistivity of $926 \Omega \times \mathrm{m}$ was found specifically at $0.437 \mathrm{~m}$ of soil depth. These data were highly correlated with the reference material used in the calibration curve of resistivity ${ }^{9}$. The results of the 2D-ERT technique were confirmed by the exploration in trial pits and by performing an XRD analysis of rock material found at the $C$ boundary, probing the existence of otavite (see Fig. 1c). However, it is not clear whether $\mathrm{Cd}$ is primarily favoured for secondary carbonate bioprecipitation (otavite) rather than other mineral forms biologically induced, such as fluorapatite, greenockite or hawleyite. The resistivity above $2000 \Omega \times \mathrm{m}$ was related to the high-density rock material and high clay content in the assessed farm.

Indeed, a segregated patchy distribution of rock material with a resistivity ranging from $850-950 \Omega \times$ was observed across the second section line (inverse model resistivity tomogram, Fig. 1b). This prospected line exhibited high SOM content with fragmented solid-state phase rocks, and rock formation was observed from underground through to the surface (1.21 m soil depth, as shown in the tomography of Fig. 1c). Thus, it is important to highlight that the 2D-ERT plot shows that, even at the same farm, the distribution of Cd in rock material in the subsoil is highly patchy and greatly heterogenous, as observed in other farms nearby. However, its distribution could be driven by outcropping rock material and ligand 
dynamics due to changes in climatic conditions such as wet or dry seasons and rock bio weathering, as previously reported ${ }^{5,27}$. Table 2 summarises the mean soil pseudo-total $\mathrm{Cd}$ content with resistivity tomography results at three sampling sites of the cropped farm and includes the determined soil $\mathrm{pH}$ and SOM values. The Pearson correlation between resistivity profiling and Cd determination by ICP-OES was high $\left(\mathrm{R}^{2}=\right.$ 0.86) considering the field data. The $\mathrm{pH}$ after fertiliser application had decreased since $\mathrm{P}$ made ligands with the $\mathrm{H}_{2}{ }^{+}$protons available in the soil solution, as has been also observed in other studies ${ }^{28,29}$.

\subsubsection{Phosphate-containing fertilisers}

It was found that two out of four phosphate-based fertilisers leached out Cd in greater levels (ranging from 3-30 mg/kg). One fertiliser of a national brand (called 'Triple 15') was shown to have $3.68 \mathrm{mg} / \mathrm{kg}$ of $\mathrm{Cd}$, whereas an international one (called '12M 15-8-12') was shown to have $29.9 \mathrm{mg} / \mathrm{kg}$ of this metal. Table 2 shows the distribution of soil P after fertilisation. Even if there is not actually a nationwide regulation for admissible Cd content or a regulation for advertising information of heavy metal content within the product label, the study of polluted fertiliser with $\mathrm{Cd}$ to avoid such input in the system should be taken into account to tackle this issue.

\subsection{Effects of post-harvest treatments on Cd concentration}

Figure 2 shows the dynamics of Cd concentration from seeds to beans and chocolate, stage by stage of its transformation. The Cd content from seeds to beans did not vary with any statistically significant difference $(p>0.05)$. The Cd content detected in those treatments showed an average value of $4.17 \pm 0.8 \mathrm{mg} / \mathrm{kg}$. Similar results were found when several spontaneous fermentations SF were carried out in other cacao-growing regions, following the same procedure and with their particular mix of cocoa varieties (See supplementary material in Table S1 and Figure S3).

Figure 3 shows the changes in $\mathrm{pH}$ and temperature during the post-harvest transformation of cocoa seeds according to the spontaneous fermentation (SF) and transformation under controlled conditions (TUCC) treatments. It is known that SF involves two transformation phases. The first corresponds to an anaerobic phase. In this phase, pectinolytic yeasts produce ethanol. Yeast populations are responsible for liquefying the mucilage, which causes pulp drainage (release by sweating) that comes out from the fermented system and allowing for the entry of oxygen into the fermented mass ${ }^{30}$. The temperature increases slowly along with the exothermal activities of yeasts and bacteria 20 . LAB use citric acid and the residual carbohydrates of the mucilage to produce lactic acid and acetic acid. The second phase corresponds to an aerobic phase, where the predominant microorganisms are acetic acid bacteria (AAB), which are involved in both ethanol and lactic acid oxidations to produce acetic acid

30 . During the aerobic phase in SF, the diffusion of ethanol, acetic acid and lactic acid into cocoa seeds occurred, causing a pH decrease from 6.5 to 4.9 inside the seeds (Fig. 3). Furthermore, in such cases, exothermic reactions occur, reaching a temperature near $45^{\circ} \mathrm{C}$ that favours the activity of endogenous enzymes, resulting in cocoa flavour precursors ${ }^{31}$ As shown in Fig. 3, during SF, a drop of pH was observed between 0 and 72 h. Then, it remained constant until $96 \mathrm{~h}$, however, increased in the last hours near to 5.5 . The temperature reached $46^{\circ} \mathrm{C}$ between $72 \mathrm{~h}$ and $96 \mathrm{~h}$; however, after $96 \mathrm{~h}$, the temperature was stable at $45^{\circ} \mathrm{C}$. Thus, the increase of $\mathrm{pH}$ values and the decrease of temperature can be explained by the activity of both the AAB and LAB populations. This inverse relationship was followed by a decreasing substrate availability and, consequently, the acidic metabolites that should migrate inside the seeds were not generated, as described previously ${ }^{32}$.

To assess whether a stronger decrease in seed $\mathrm{pH}$ over time has an effect on Cd concentration, this variable was analysed using the TUCC treatment with two weak acids, acetic and lactic acid, using a temperature gradient along the process. In Fig. 3, it was observed that the pH decreased from 6.5 to 4.5 in both treatments between $0-72 \mathrm{~h}$ of fermentation; however, after $120 \mathrm{~h}$, a second pH decrease was observed reaching 4.4 and 4.0 units in the TUCC-AA and TUCC-LA treatments, respectively. Hence, in these results the postharvest process established more acidic pH conditions for seed transformation.

In both the SF and TUCC treatments, despite the observed dynamics, there was no statistically significant variance ( $p>0.05)$ in Cd content of the seeds. These results are not in concordance with those reported in a recent work ${ }^{33}$, where the migration of Cd from the seeds to the testa was observed when the seed $\mathrm{pH}$ dropped below 5 , and the acidic $\mathrm{pH}$ was determined to have resulted from a longer fermentation time (up to seven days). In contrast, as shown in Fig. 3, although a pH value $<5.0$ was reached between 72 and $96 \mathrm{~h}$ for the SF treatment, a decrease in Cd content was not observed in the seeds at all. Additionally, when the SF treatment time was prolonged, the pH increased again; thus, the hypothesis of a recent study ${ }^{33}$ which argued that a $\mathrm{pH}<5$ and extending the fermentation more than seven days, will favour the Cd migration during fermentation, is not supported by our study. The same pH kinetic decrease of the values until 72 hours and then increasing were observed in several fermentation trials performed into other regions (See the Supplementary Figure S3). Conversely, long fermentation times may cause overfermentation, blackening of the cocoa seeds and the development of off-flavours caused by bacilli and filamentous fungi related to saprophytic activity ${ }^{32}$. Otherwise, the strongest and most sustained drop in pH over time was found when performing the cocoa transformation process with the assessed acids within the TUCC treatment, but it did not cause a lower concentration of Cd in the cocoa seeds at day 5 of fermentation even with $\mathrm{pH}$ values below 4.5 .

The effect of drying on Cd seed content was studied here. This was assessed on unfermented seeds to evaluate the direct effect of drying, and a sample of previously fermented cocoa seeds were evaluated for the possible effect of endogenous bacterial populations that had participated in

Page $4 / 16$ 
the process. There was no statistically significant variation $(p>0.05)$ in the Cd content of those samples.

When processing cocoa beans into chocolate, looking at the mass balance, even if the cocoa content varies from step to step of processing, the $\mathrm{Cd}$ content did not. During cocoa transformation from beans to nibs, especially in the roasting and deshelling operations, Cd contents of 3.28 and $6.57 \mathrm{mg} / \mathrm{kg}$ were observed in the nibs and testa, respectively. Therefore, our data suggest that the Cd content in the testa was significantly higher than in the nibs $(p<0.05)$. Similar findings were observed in another study ${ }^{21}$.

When the Cd content was assessed through the transformation of nibs into chocolate, made with $50 \%$ (w/w) of nibs, it was found that chocolate exhibited a Cd content of $1.60 \mathrm{mg} / \mathrm{kg}$, which is, as expected, almost $50 \%$ of the reported Cd value in nibs before. Thus, the decrease of Cd content is due to the chocolate making process, specifically, by the percentage of nibs used in this process (50\%) in its total mass balance. These results are similar to those of a recent study ${ }^{24}$, where it is stated that Cd contents in chocolate are closely related to the percent of cocoa solids and cacao origin, highlighting that chocolates from Central and South America usually tend to have higher contents of this metal than those from elsewhere. Furthermore, our results support the perception that lower $\mathrm{Cd}$ concentrations in the final product are the result of winnowing the testa 34 , which have no utility for chocolate production.

\section{Discussion}

Figure 4 shows the change of $\mathrm{Cd}$ content from both soil/fertiliser application to post-harvesting/chocolate production, in a single farm with $\mathrm{Cd}$ issues. Despite the fact that the $\mathrm{Cd}$ content found in the chocolate of this farm was above the mandatory regulated level approved by the Codex Alimentarius ${ }^{35}$, an integration of innovative remediation methods, from soils to chocolate, could be designed.

Our findings indicate that no process, either physical ( $\mathrm{pH}$, temperature or oxygen concentration) or chemical (enzymatic and catalytic reactions) that occur during the post-harvest transformation of cocoa seeds to beans and chocolate, help to decrease Cd content in cocoa beans. Thus, a window for microbiological evaluations is open to follow up in further studies.

Over the past two years, more research has been focusing on reducing higher Cd contents in both soils and crop management but also in the postharvest state by using several approaches without decreasing chocolate quality. The bioremediation processes, i.e., by bioaugmentation of both soil Cd-tolerant bacterial (CdtB) and cocoa bean endophytic bacterial populations (ECdtB), could remove Cd in several steps of the cacao system 5

Further research should be conducted to tackle the origin and distribution of $\mathrm{Cd}$ in soils in consideration of soil chemistry and fertiliser input, as well as, the importance of the cacao variety used in farms, the age the trees and crop losses and management ${ }^{36}$ in the function of Cd fluxes through the system. Knowledge about difference in the translocation and bioaccumulation rate in cacao varieties is scarce, showing that more physiological and agroforestry studies are also required. Moreover, future studies should focus on designing and developing post-harvest treatments including bioremediation or the use of nanoparticles (i.e. Ag-NPs) to chelate Cd content at the very last stages for chocolate production to avoid losses in quality while still maintaining its safety, complying to cadmium threshold.

The presence of $\mathrm{Cd}$ in cacao plantations is a challenge. However, there are now opportunities to understand how it fluxes through the system. The biogeochemistry of the system has the influence of exerting a final deposition of $\mathrm{Cd}$ in beans or chocolate. Even so, if it is the starting point of the system, it is not the only one. The contamination by $\mathrm{Cd}$ is due, in part, to the low buffering capacity of acidic tropical soils whereas cacao is cropped. Therefore, higher levels of $\mathrm{Cd}$ are also related to soil acidification (the value of $2.38 \mathrm{mg} / \mathrm{kg}$ should be considered as contaminated in soils), as observed in cases of low pH values such as these found in the assessed farm, from 4.7 to 4.9 , where Cd is more active chemically and therefore available for cacao uptake. Under acidic conditions, the electronegative property of Cd allows for the metal to be very labile in the system, increasing the translocation ratios as we observed in the case of Cd content in cocoa seeds or beans in this particular farm (where soil/bean ratios above $1 \mathrm{mg} / \mathrm{kg}$ are considered high). In comparison with other elements such as $\mathrm{Pb}$, Cd is much more labile, as has been described.

Reducing the available $\mathrm{Cd}$ in chemical species such as $\mathrm{Cd}$ hydroxides, $\mathrm{Cd}$ carbonates or even $\mathrm{Cd}$ sulphates by increasing soil pH values is a first step to suggest for this farm. As shown, the Cd content of P-based fertilisers is a second input in the system. The final disposition of this input is reflected in the $\mathrm{Cd}$ beans as a function of bioaccumulation.

In this study, no significant changes were observed following a variety of post-harvest and processing treatments that allow the physical and biochemical transformation of the seeds to beans and to chocolate. However, peeling the testa decreases the Cd content of nibs and it was shown to be the most likelihood short-term strategy to reducing it. Therefore, performing an integrative diagnosis of Cd is a critical component in managing $\mathrm{Cd}$ content through the system. The picture shown here of a single farm suggests that by using the biology of the system (mainly using CdtB and ECdtB), the chemical speciation of $\mathrm{Cd}$ in the soils might change, with a decreasing effect of final deposition in beans and favouring the sequestering of $\mathrm{Cd}$ in geostable forms into the soil. By performing a detailed diagnosis of the system, a sound strategy could be properly designed to change the $\mathrm{Cd}$ content of enriched farms. 


\section{Methods}

\subsection{Selecting the farm}

A farm in the district of Santander was selected due to i. the economic and social importance of cocoa in the district; ii. the known problem of cadmium in the cocoa-chocolate value chain in Santander iii. the diversity of the cocoa materials produced in Santander, comprising both international materials such as CCN51, EET8, IMC67, ICS1, ICS95, TSH565 and ICS60, and regional materials such as TCS01, TCS06, FEC2 and FSV41; iv. Record of the highest soil Cd content found in the district ${ }^{9}$ and v. the appropriate level of technology in terms of methods and systems for post-harvest based on the processing criteria to obtain high quality cocoa products ${ }^{37}$.

The farm comprised an intercropping system of cacao trees separated from one another by $4 \mathrm{~m}$, interspersed with two timber wood species (Ceiba tolua and Cedrus brevifolia). The cacao trees were eight years old in average to all the varieties found. Five kilos of fresh cacao pods and $500 \mathrm{~g}$ of composite soil samples were collected one month after pruning.

\subsection{Soil Cd distribution and quantitation: From soils to cocoa seeds}

Soil Cd distribution was monitored using an electrical resistivity tomography (2D-ERT) profiling in order to obtain an initial image of possible hot spots of $\mathrm{Cd}$ in the rhizospheric soil. The technique was performed according to the specifications in a previous study ${ }^{9}$, using $\mathrm{Cd}$ carbonate and Cd sulphate as soluble and insoluble sources of cadmium, respectively. The plot of soil where the resistivity tomography was assessed, was representative of the farm since the topography and the stratigraphy data did not showed representative differences ( $p$-value $<0.05)$. The resistivity profiles were used to excavate soil trial pits, from which soil samples were taken at each soil boundary related to the cacao rhizosphere. The 2D-ERT profiles were obtained after a calibration test for the soil samples collected all across the plot selected. To calibrate the resistivity of cadmium-like compounds, three commercial reference reagents were used during the calibration of the technique as a proxy for the stable Cd forms that might be found in field. The references were otavite, greenockite and sphalerite in three concentrations (0.5, 1 and $2 \mathrm{mg} / \mathrm{kg}$ ), with $97 \%$ purity (w/w). Soil samples were obtained using Stanley stainless steel Shelby tubes of $20 \mathrm{~cm}$ in length (RA Ltda, Bogotá, Colombia). Composite soil samples were obtained by mixing $500 \mathrm{~g}$ of soil collected within the Shelby tubes of the single boundaries. The samples were placed separately in plastic zip bags, according to the soil boundary, stored at $4{ }^{\circ} \mathrm{C}$ and sent to the Laboratory of Soil Microbiology \& Calorimetry of the Corporación Colombiana de Investigación Agropecuaria, AGROSAVIA, in Mosquera, Colombia. The samples were then analysed following the extraction protocol used to quantify the Cd values obtained from another study ${ }^{12}$.

Soil Cd content was quantified using an inducted conductive plasma spectrometer ICP-OES (Thermo ICAP-6500, ThermoFisher Scientific Inc., NY, USA) using the methodology previously described ${ }^{5}$. Cd content was determined at each boundary and spot selected according to the $2 \mathrm{D}$-ERT profiles. The spectrometric determinations were carried out in replicates, and the standard deviations are shown graphically as vertical bars. To compare with the soil samples collected, a standard reagent of clay soil WEPAL ISE 961 (0.8 mg/kg Cd; Herveld, The Netherlands) and a clay soil WEPAL ISE970 (7.04 mg/kg Cd; River clay from Netherlands), were used and a standard curve of calibration was performed.

\subsubsection{Soil $\mathrm{pH}$ and SOM determination}

Soil $\mathrm{pH}_{[\mathrm{H} 2 \mathrm{O}]}$ was measured with a multi-parameter electrode (YSI $556 \mathrm{OH}, \mathrm{US}$ ) at each boundary of the rhizoplane pits. Soil organic matter (SOM) and phosphorus content were determined by atomic absortion spectrometry (IAA) using the digestion protocol applied in a previous study ${ }^{5}$.

\subsubsection{Assessing fertiliser amendments}

A pool of 13 phosphate-containing fertilisers were selected to be analysed for $\mathrm{Cd}$ content. The fertilisers were selected by taking into account the farmers' preferences for application. This is important in order to perform a good diagnosis of the reliable Cd inputs. Five commercial brands belonged to international companies, and two local produced brands within the national market were tested for Cd. The digestion method and determinations were performed according to the international EPA method 6010C, as reported in previous studies ${ }^{38,39}$.

\subsection{Post-harvest treatments: From seeds to beans and to chocolate}

In terms of analysing the different possibilities of $\mathrm{Cd}$ flux depending on the postharvest operation influence, we submitted the same batch of fresh seeds to the three possibilities of kind of postharvest transformation processes (Fig. 5), using three experimental conditions i. Two operations were assessed between the transformation from seeds to beans based on previous work ${ }^{19}$, on the one hand, a natural spontaneous fermentation process (SF); and on the other hand, a transformation under controlled conditions using acidic solutions. This latter treatment was used to evaluate the effect of $\mathrm{pH}$ on the $\mathrm{Cd}$ content of seeds when they were subjected to more acidic conditions. ii. Only drying, and iii. during the processing of the nibs into chocolate, where roasting was considered. Table 1 shows the samples derived from the treatments previously defined.

\subsubsection{Spontaneous fermentation (SF)}

Page 6/16 
A trial of SF was developed in the selected farm for the above - mentioned mix of cocoa materials (Supplementary Figure S1). Only mature and healthy pods were selected for this trial. The pods were harvested, and seeds were removed. Fifty kg of fresh seeds from a mix of cocoa material were placed in each of 6 compartments of the wooden fermenter shown in Fig. 6 . This fermenter system allowed to establish 6 fermentations as repetitions of the assay. Any contact with the steel nails was avoided, ensuring no interference with the Cd determination in the seed matrix. The SF lasted $120 \mathrm{~h}$, and the anaerobic phase was maintained for $48 \mathrm{~h}$. The aeration of the beans was performed manually every $12 \mathrm{~h}$ by moving them from one compartment to another. The cut test was carried out every 24 hours to measure the fermentation degree of cocoa seeds. The internal temperature of the cocoa mass at the central point of each compartment of the fermenter system was monitored throughout the fermentation time with a thermocouple (Testo-735-1). The internal seed $\mathrm{pH}$ was determined by applying a protocol established in another study 40 . For this, first the testa of the seed was removed and then the seed was ground with a blade grinder. Furthermore, $2.5 \mathrm{~g}$ of ground material was suspended in $22.5 \mathrm{~mL}$ MilliQ water in $50 \mathrm{~mL}$ centrifuge tubes and shaken head - over - head for 5 min. The suspension was centrifuged at 1000 rpm for $10 \mathrm{~min}$, and the pellet was discarded. A pH meter (Mettler Toledo, Giessen, Germany) was used to measure the pH of the supernatant.

\subsubsection{Transformation under controlled conditions (TUCC) using acidic solutions: acetic acid and lactic acid}

The TUCC treatment was developed according to the protocol reported by Santander et al., 2020 In prep. This is a process by which the cocoa seeds from the mix of cacao materials mentioned above, were transformed through the simulation of the conditions of SF occurring on the field (Supplementary Figure S2). The TUCC process was developed under sterile conditions, for this, all equipment used was autoclaved or wiped with $70 \%$ ethanol. One $\mathrm{kg}$ of fresh seeds of the mix of cocoa materials were de-pulped using sterilised plastic mesh pads under inside a laminar flow work bench. Seeds were rinsed in $70 \%$ ethanol for $1 \mathrm{~min}$ in order to exclude any remaining microorganisms on the surfaces of the seeds. Two trials of TUCC were run using independently two fermentation by-products as experienced in a spontaneous fermentation: acetic acid (TUCC-AA) $\left(\mathrm{CH} \otimes \mathrm{COOH}, 100 \%\right.$, Merck, Darmstadt, Germany), and lactic acid (TUCC-AL) $\left(\mathrm{C}_{3} \mathrm{H}_{6} \mathrm{O}_{3}, 98 \%\right.$, Merck, Darmstadt, Germany) that were used as incubation media to investigate the effect of $\mathrm{pH}$ on the cadmium concentration in the seeds. Both, TUCC-AA and TUCC-LA carried out in triplicate. TUCC was carried out in 36 of 500 ml Erlenmeyers. 45 cocoa seeds were placed in such glass flasks containing $280 \mathrm{ml}$ of the incubation media. The incubation media contained acetic acid or lactic acid at $30 \mathrm{~g} / \mathrm{L}$. The glass flasks were placed in incubators under shaking at $200 \mathrm{rpm}$. The incubation temperature was adjusted to $30^{\circ} \mathrm{C}$ on day one, $35^{\circ} \mathrm{C}$ on day two, $45^{\circ} \mathrm{C}$ until the end of the process. The pH was measured from each replica every $24 \mathrm{~h}$. Ten g of cocoa seeds were collected from the six Erlenmeyers and stored at $-20^{\circ} \mathrm{C}$ until analysis.

\subsubsection{Seeds and beans sampling}

Table 1 describes the treatments used to evaluate the $\mathrm{Cd}$ content of the seeds and beans during the post-harvest processes. In the case of SF, for all Cd analyses, a sample was obtained from a mix of cocoa seeds which was taken from three parts of the fermentation chamber: upper, middle and bottom zone. This sampling method was repeated for each of the six compartments of the fermenter (six replicas for each sample). For fresh seeds and fermented cocoa seeds, six samples of $100 \mathrm{~g}$ of seeds were sampled and stored in sterile plastic zip bags at $-80^{\circ} \mathrm{C}$ until further analysis. For the unfermented and only dried cocoa beans, six samples of $100 \mathrm{~g}$ of fresh seeds, as replicas, were sampled from the upper, middle, and lower zone of the initial fermentation cocoa mass and placed in a drying system. For chocolate production, $300 \mathrm{~g}$ of fermented cocoa seeds from the fifth day of each of the six compartments of the wooden fermenter were sampled and dried at $50^{\circ} \mathrm{C}$ for three days and stored in bags at $25^{\circ} \mathrm{C}$. For the TUCC treatment, from each of the three replicas, $30 \mathrm{~g}$ of cocoa seeds from fifth day of the process were sampled for analysis. The drying operation by sun exposure lasted $120 \mathrm{~h}$. The beans were extended in a drying system composed of a sliding roof and a wooden platform. The end of the drying step was determined when cocoa beans reached an approximated moisture below $7 \%$ (w/w) ${ }^{41}$

\subsubsection{Chocolate production: From beans to bar}

Chocolate production was completed in the Chocolate Factory Laboratory of the Institute of Food and Beverage Innovation of the University of Applied Sciences (Zürich, Switzerland) by a standard protocol ${ }^{42}$. The chocolate samples were produced with the $50 \%$ (w/w) of the nibs from the whole cocoa beans.

\subsubsection{Cd determination in post-harvested samples}

A microwave- assisted acid digestion protocol was applied to the seeds and beans according to the protocol of a previous study ${ }^{43}$ with some modifications. Briefly, the modifications consisted of using $4 \mathrm{~mL}$ of concentrated Suprapur ${ }^{\circledR}$ nitric acid (HNOQ, 65\% w/w, Merck, Darmstadt, Germany) and $1 \mathrm{~mL}$ of hydrogen peroxide $\left(\mathrm{H}_{2} \mathrm{O}_{2}, 30 \% \mathrm{w} / \mathrm{w}\right.$, Merck, Darmstadt, Germany) together with $0.8 \mathrm{~g}$ of sample. The samples were heated in a microwave unit at $1500 \mathrm{~W}$ and $220^{\circ} \mathrm{C}$ for $20 \mathrm{~min}$ with a pressure of $150 \mathrm{bars}$. The digested samples were diluted to $30 \mathrm{~mL}$ with nano-pure distilled water and filtered using a $0.45 \mu \mathrm{m}$ membrane filter prior to the Cd counts.

The content of $\mathrm{Cd}$ in the samples was quantified by ICP-OES, using the same instrument utilized to perform the Cd determinations for the soil (Thermo iCAP-6500, ThermoFisher Scientific Inc., NY, USA).

The limit of quantification (LOQ) for the ICP-OES analysis was $0.28 \mathrm{mg} / \mathrm{kg}$ dry matter. For all Cd analysis, triplicates were included every 15 samples to evaluate reproducibility. The coefficient of variation (CV) for the triplicate digestions ranged 0.9-25\% (average CV $7 \%$ ). The certified

Page $7 / 16$ 
reference material WEPAL-IPE-213 Milk Thistle Seed/Silybum marianum (Cd $0.355 \pm 0.016 \mathrm{mg} / \mathrm{kg}$ ) was included in all digestions and treated the same way as the cocoa derived samples for quality assurance. The recoveries of $\mathrm{Cd}$ regard to the certified reference material was $93 \% \pm 8.5$ for seeds and beans.

\subsection{Data analysis}

\subsubsection{Soil}

A test for ANOVA was performed in order to compare differences in the means between both soils' Cd contents and the Cd contents of the fresh seeds and fermented and dried beans. A Tukey test was performed to observe the meaningful differences $(p<0.05)$. A Pearson correlation was calculated for soil resistivity $(\Omega \times \mathrm{m})$ and soil Cd content $(\mathrm{mg} / \mathrm{kg})$ to compare the 2D-ERT profiles with the spectrometric Cd determinations. The $\mathrm{Cd}$ content of both the soils and post-harvest treatments were plotted in a single representation. The statistical analysis was performed using QtiPlot.

\subsubsection{Post-harvest treatments and Chocolate production}

Data were processed using R v. 3.6.0 software and graphs (Cd contents in fermented seeds and pH dynamics from different Colombian regions) were constructed using OriginLab 2015. Cd concentration means and standard errors of the mean were calculated for all samples mentioned in Table 1. To establish significant differences among samples derived from the different postharvest treatments (to independently compare, on the one hand, the samples from 1 to 10 and, on the other hand, the samples 10 to 13 of Table 1), F tests were calculated in the ANOVA and then a post-hoc Tukey's HSD (Honestly Significant Difference) test was carried out, to identify significantly different samples regarding their Cd contents. Statistical significance was established at $p<0.05$.

\section{Declarations}

\section{Acknowledgements}

We gratefully acknowledge the generous assistance provided by unknown reviewers of this manuscript. The samples were collected according to the Colombian Resolution No. 1466 of $3^{\text {rd }}$ December 2014, by which AGROSAVIA has collected permission to perform biological diversity sampling for non-commercial and scientific research purposes. We also would like to acknowledge to Dr. Rachel Atkinson from Bioversity Peru for proofreading this manuscript, to Dr. Eduardo Chávez from ESPOL University in Guayaquil, Ecuador, for Cd determination in chocolate samples. We also thanks to MSc. Javier Benavides-Erazo for advice and performing the ERT profiles on field in the assessed farm and to Iván Chacón-Garzón for the design drawings of the fermenter system.

\section{Contributions}

DB: conceived and designed the experiments; performed the experiments; analysed and interpreted the data; contributed reagents, materials, analysis tools or data; drawn figures; wrote the paper. MS: performed the experiments; analysed and interpreted the data; drawn figures; wrote the paper. JR: conceived and designed the experiments; performed the experiments; analysed and interpreted the data; analysis tools or data; wrote the paper. SE: conceived and designed the experiments; performed the experiments; analysed and interpreted the data; contributed reagents, materials, analysis tools or data; drawn figures; wrote the paper.

\section{Funding statement}

This work was supported by the Corporación Colombiana de Investigación Agropecuaria AGROSAVIA, through grants No. 1000664 and 1001134 as part of the internal projects of the research agenda entitled 'Cd in cacao and the strategies to tackle it' and 'Cacao in post-harvest processes'. This study was also supported by the Colombian Ministry of Agriculture and Rural Development (MADR).

\section{Competing interest statement}

The authors declare no conflict of interest.

\section{Data Availability}

The datasets generated during and/or analysed during the current study are not publicly available due to the susceptibility of farmer owner, but are available from the corresponding author on reasonable request

\section{References}

1. FEDECACAO. Cifras Fondo Nacional del Cacao. https://www.fedecacao.com.co/portal/index.php/es/2015-2002-2012-2017-20202059/nacionales (2020). 
2. European, C. 5-5 (European Commission, Belgium, 2014).

3. WHO. (Belgium, 2019).

4. Arévalo-Gardini, E., Arévalo-Hernández, C. O., Baligar, V. C. \& He, Z. L. Heavy metal accumulation in leaves and beans of cacao (Theobroma cacao L.) in major cacao growing regions in Peru. Sci Total Environ 605-606, 792-800, doi:https://doi.org/10.1016/j.scitotenv.2017.06.122 (2017).

5. Bravo, D. et al. Soil cadmium tolerant-immobilizing bacteria in cocoa crops from northeastern Colombia. J App/ Microbio/ 124, 1175-1194, doi:10.1111/jam.13698 (2018).

6. Kaya, M. A., Özürlan, G. \& Şengül, E. Delineation of soil and groundwater contamination using geophysical methods at a waste disposal site in Çanakkale, Turkey. Environ Monit Assess 135, 441-446, doi:10.1007/s10661-007-9662-x (2007).

7. Kruszewski, B., Obiedziński, M. W. \& Kowalska, J. Nickel, cadmium and lead levels in raw cocoa and processed chocolate mass materials from three different manufacturers. J Food Compos Ana/ 66, 127-135, doi:https://doi.org/10.1016/j.jfca.2017.12.012 (2018).

8. Domra Kana, J., Djongyang, N., Danwe, R., Njandjock Nouck, P. \& Abdouramani, D. A review of geophysical methods for geothermal exploration. Renew Sust Energ Rev 44, 87-95, doi:http://dx.doi.org/10.1016/j.rser.2014.12.026 (2015).

9. Bravo, D. \& Benavides-Erazo, J. The use of a two-dimensional electrical resistivity tomography (2D-ERT) as a technique for cadmium determination in cacao crop soils. App/ Sci 10, 1-16, doi:https://doi.org/10.3390/app10124149 (2020).

10. Arjwech, R., Sriwangpon, P., Somchat, K., Pondthai, P. \& Everett, M. Electrical resistivity tomography (ERT) data for clay mineral mapping. Data in Brief 30, 1-5, doi:https://doi.org/10.1016/j.dib.2020.105494 (2020).

11. Alloway, B. J. \& Steinnes, E. in Cadmium in soils and plants (eds M. J. McLaughlin \& B. R. Singh) 97-123 (Springer Netherlands, 1999).

12. Chavez, E. et al. Chemical speciation of cadmium: An approach to evaluate plant-available cadmium in ecuadorian soils under cacao production. Chemosphere 150, 57-62, doi:https://doi.org/10.1016/j.chemosphere.2016.02.013 (2016).

13. Gramlich, A. et al. Cadmium uptake by cocoa trees in agroforestry and monoculture systems under conventional and organic management. Sci Total Environ 580, 677-686 (2017).

14. Grant, C. A., Bailey, L. D., Mclaughlin, M. J. \& Singh, B. R. in Cadmium in soils and plants (eds M. J. McLaughlin \& B. R. Singh) 151-198 (Springer Netherlands, 1999).

15. Engbersen, N. et al. Cadmium accumulation and allocation in different cacao cultivars. Sci Total Environ 678, 660-670, doi:https://doi.org/10.1016/j.scitotenv.2019.05.001 (2019).

16. Argüello, D. et al. Soil properties and agronomic factors affecting cadmium concentrations in cacao beans: A nationwide survey in Ecuador. Sci Total Environ 649, 120-127, doi:https://doi.org/10.1016/j.scitotenv.2018.08.292 (2019).

17. Ramtahal, G., Umaharan, P., Hanuman, A., Davis, C. \& Ali, L. The effectiveness of soil amendments, biochar and lime, in mitigating cadmium bioaccumulation in Theobroma cacao L. Sci Total Environ 693, 1-11, doi:https://doi.org/10.1016/j.scitotenv.2019.07.369 (2019).

18. Welch, R. M. \& Norvell, W. A. in Cadmium in soils and plants (eds M. J. McLaughlin \& B. R. Singh) 125-150 (Springer Netherlands, 1999).

19. Santander, M., Rodríguez, J., Vaillant, F. \& Escobar, S. An overview of the physical and biochemical transformation of cocoa seeds to beans and to chocolate: flavor formation. Crit Rev Food Sci 60, 1593-1613, doi:10.1080/10408398.2019.1581726 (2019).

20. Pacheco-Montealegre, M. E., Dávila-Mora, L. L., Botero-Rute, L. M., Reyes, A. \& Caro-Quintero, A. Fine resolution analysis of microbial communities provides insights into the variability of cocoa bean fermentation. Front Microbio/ 11, 650-650, doi:10.3389/fmicb.2020.00650 (2020).

21. Lewis, C., Lennon, A. M., Eudoxie, G. \& Umaharan, P. Genetic variation in bioaccumulation and partitioning of cadmium in Theobroma cacao L. Sci Total Environ 640-641, 696-703, doi:https://doi.org/10.1016/j.scitotenv.2018.05.365 (2018).

22. Żyżelewicz, D. et al. The influence of the roasting process conditions on the polyphenol content in cocoa beans, nibs and chocolates. Food Res Int 89, 918-929, doi:https://doi.org/10.1016/j.foodres.2016.03.026 (2016).

23. Vanderschueren, R., Montalvo, D., De Ketelaere, B., Delcour, J. A. \& Smolders, E. The elemental composition of chocolates is related to cacao content and origin: A multi-element fingerprinting analysis of single origin chocolates. J Food Compos Ana/ 83, 1-7, doi:https://doi.org/10.1016/j.jfca.2019.103277 (2019).

24. Abt, E., Fong Sam, J., Gray, P. \& Robin, L. P. Cadmium and lead in cocoa powder and chocolate products in the US Market. Food Addit Contam B 11, 92-102, doi:10.1080/19393210.2017.1420700 (2018).

25. Lo Dico, G. M. et al. Toxic metal levels in cocoa powder and chocolate by ICP-MS method after microwave-assisted digestion. Food Chem 245, 1163-1168, doi:https://doi.org/10.1016/j.foodchem.2017.11.052 (2018).

26. Mrmošanin, J. M. et al. Multielemental quantification in dark chocolate by ICP OES. J Food Compos Anal 67, 163-171, doi:https://doi.org/10.1016/j.jfca.2018.01.008 (2018).

27. Liu, Y. et al. Geogenic cadmium pollution and potential health risks, with emphasis on black shale. J Geochem Explor 176, 42-49, doi:https://doi.org/10.1016/j.gexplo.2016.04.004 (2017).

Page $9 / 16$ 
28. McLaughlin, M. J. \& Singh, B. R. in Cadmium in soils and plants (eds M. J. McLaughlin \& B. R. Singh) 1-9 (Springer Netherlands, 1999).

29. Mourato, M. et al. in Cadmium toxicity and tolerance in plants (eds Mirza Hasanuzzaman, Majeti Narasimha Vara Prasad, \& Masayuki Fujita) 327-348 (Academic Press, 2019).

30. Nielsen, D. S., Crafack, M., Jespersen, L. \& Jakobsen, M. in Chocolate in health and nutrition (eds Ronald Ross Watson, Victor R. Preedy, \& Sherma Zibadi) 39-60 (Humana Press, 2013).

31. Pacheco-Montealegre, M. E., Dávila-Mora, L. L., Botero-Rute, L. M., Reyes, A. \& Caro-Quintero, A. Fine grained longitudinal analysis of cocoa bean fermentation provides insights into the dynamics of microbial populations. bioRxiv, 1-15, doi:10.1101/702225 (2019).

32. De Vuyst, L. \& Weckx, S. The cocoa bean fermentation process: from ecosystem analysis to starter culture development. J App/ Microbio/ 121, 5-17, doi:10.1111/jam.13045 (2016).

33. Vanderschueren, R. et al. The impact of fermentation on the distribution of cadmium in cacao beans. Food Res Int 127, 1-9, doi:https://doi.org/10.1016/j.foodres.2019.108743 (2020).

34. Okiyama, D. C. G., Navarro, S. L. B. \& Rodrigues, C. E. C. Cocoa shell and its compounds: Applications in the food industry. Trends Food Sci Tech 63, 103-112, doi:https://doi.org/10.1016/j.tifs.2017.03.007 (2017).

35. FAO/WHO. (Netherlands, 2018).

36. Maddela, N. R. et al. Cocoa-laden cadmium threatens human health and cacao economy: A critical view. Sci Total Environ 720, 1-15, doi:https://doi.org/10.1016/j.scitotenv.2020.137645 (2020).

37. Escobar, S., Santander, M., Useche, P., Contreras, C. \& Rodríguez, J. Aligning strategic objectives with research and development activities in a soft commodity sector: A technological plan for Colombian cocoa producers. Agriculture 10, 1-32, doi:https://doi.org/10.3390/agriculture10050141 (2020).

38. Rocco, C. et al. Impact of waste-derived organic and inorganic amendments on the mobility and bioavailability of arsenic and cadmium in alkaline and acid soils. Environ Sci Pollut R 25, 25896-25905, doi:10.1007/s11356-018-2655-1 (2018).

39. Wiggenhauser, M. et al. Using isotopes to trace freshly applied cadmium through mineral phosphorus fertilization in soil-fertilizer-plant systems. Sci Total Environ 648, 779-786, doi:https://doi.org/10.1016/j.scitotenv.2018.08.127 (2019).

40. John, W. A. et al. Forcing fermentation: Profiling proteins, peptides and polyphenols in lab-scale cocoa bean fermentation. Food Chem 278, 786-794, doi:https://doi.org/10.1016/j.foodchem.2018.11.108 (2019).

41. Zahouli, B. et al. Effect of drying methods on the chemical quality traits of cocoa raw material. Adv J Food Sci Technol 2, 184-190, doi:http://www.researchgate.net/publication/45492320_Effect_of_Drying_Methods_on_the_Chemical_Quality_Traits_of_Cocoa_Raw_Material. (2010).

42. Chetschik, I., Pedan, V., Chatelain, K., Kneubühl, M. \& Hühn, T. Characterization of the flavor properties of dark chocolates produced by a novel technological approach and comparison with traditionally produced dark chocolates. J Agr Food Chem 67, 3991-4001, doi:10.1021/acs.jafc.8b06800 (2019).

43. Jackson, E., Farrington, D. S. \& Henderson, K. The analysis of agricultural materials: a manual of the analytical methods used by the agricultural development and advisory service. (1986).

\section{Tables}


Table 1.

Cocoa seeds postharvest treatments and sampling stages to analyse the dynamics of the cadmium content along of them.

\begin{tabular}{|lll|}
\hline Treatment & Stage & Sample \\
\hline 1 & Harvest & Fresh seeds \\
\hline 2 & Spontaneous fermentation & Seeds day 1 \\
\hline 3 & & Seeds day 2 \\
\hline 4 & & Seeds day 3 \\
\hline 5 & & Seeds day 4 \\
\hline 6 & Transformation under controlled conditions with acetic acid (TUCC-AA) & Seeds day 5 \\
\hline 7 & Transformation under controlled conditions with lactic acid (TUCC- LA) & Seeds day 5 \\
\hline 8 & Drying & Seeds day 5 \\
\hline 9 & & Fermented and dried seeds \\
\hline 10 & Roasting & Only dried seeds \\
\hline 11 & & Nibs \\
\hline 12 & & Testa \\
\hline 13 & & Chocolate \\
\hline
\end{tabular}

Table 2.

Soil Cd, pH, SOM, P content and resistivities in the soil boundaries assessed at the selected farm.

\begin{tabular}{|c|c|c|c|c|c|c|c|}
\hline Boundary & Soil depth [cm] & Soil Cd [mg/kg] & Resistivity [Ohm $\times \mathrm{m}]$ & SOM \% & $\mathrm{pH}$ & $\mathrm{P}[\mathrm{mg} / \mathrm{kg}]$ & Cd fertilisers $[\mathrm{mg} / \mathrm{kg}]$ \\
\hline Ap & $+3-0 *$ & $1.15 \pm 0.20$ & $950 \pm 14$ & 3.78 & 4.7 & 132.45 & $3-30$ \\
\hline$A$ & $0-20$ & $1.37 \pm 0.40$ & $477 \pm 92$ & 1.87 & 5 & 68.66 & \\
\hline B & $21-72$ & $2.38 \pm 0.30$ & $926 \pm 70$ & 2.93 & 4.9 & 120.62 & \\
\hline C & $73-100$ & $0.42 \pm 0.70$ & $370 \pm 22$ & 1.24 & 6.2 & 54.76 & \\
\hline
\end{tabular}

$\star+3=3 \mathrm{~cm}$ above surface, mainly litter.

\section{Appendix}

\section{Appendix A. Supplementary data}

Supplementary data to this article can be found online.

\section{Figures}




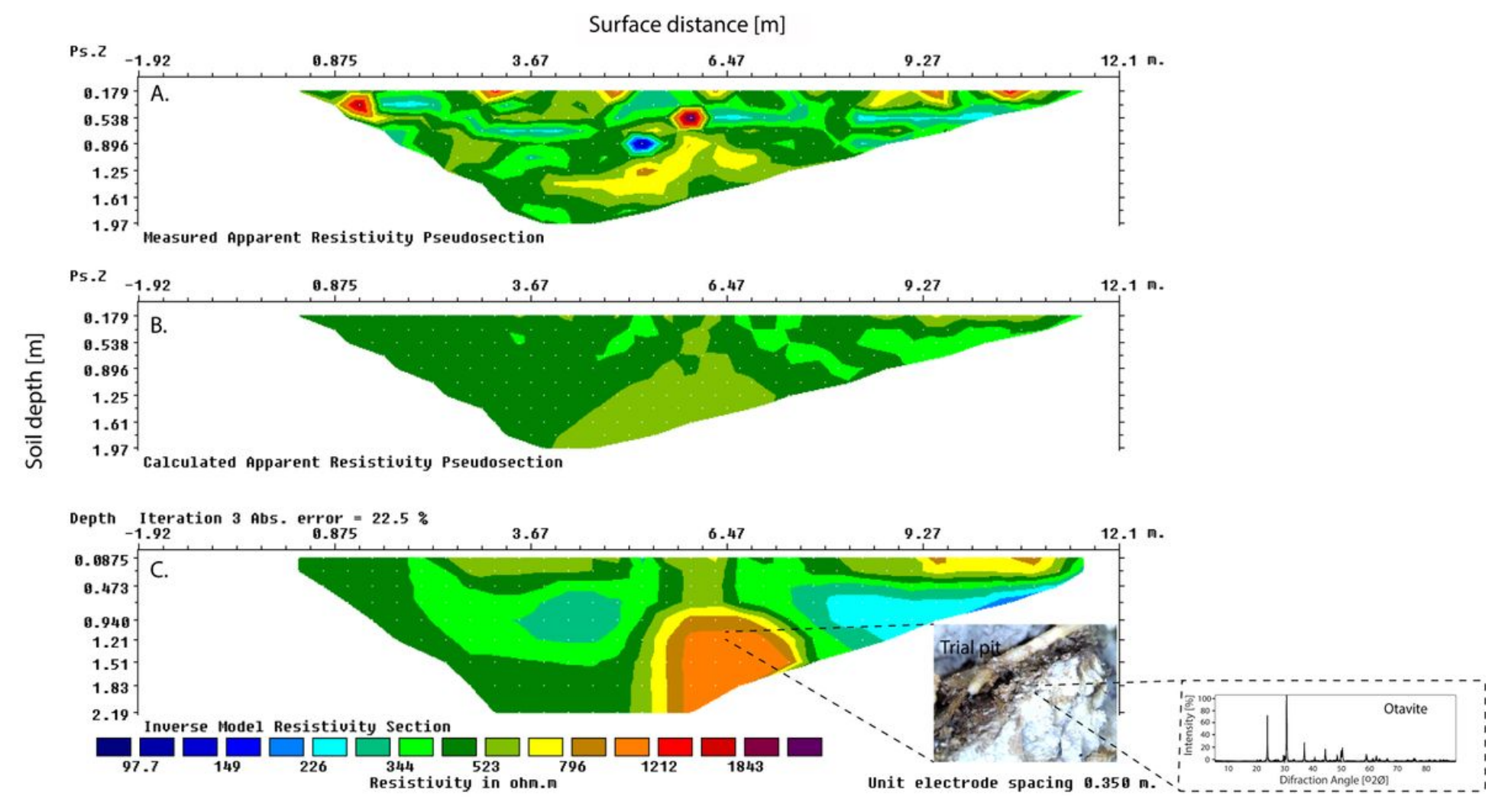

\section{Figure 1}

2D - ERT plots of a. measured apparent resistivity, b. calculated apparent resistivity and c. inverse model resistivity in both, the topsoil and subsoil of cacao in a selected farm in Santander. The red-violet colours are close to the Cd enrichments or soil hot-spots of the metal. 


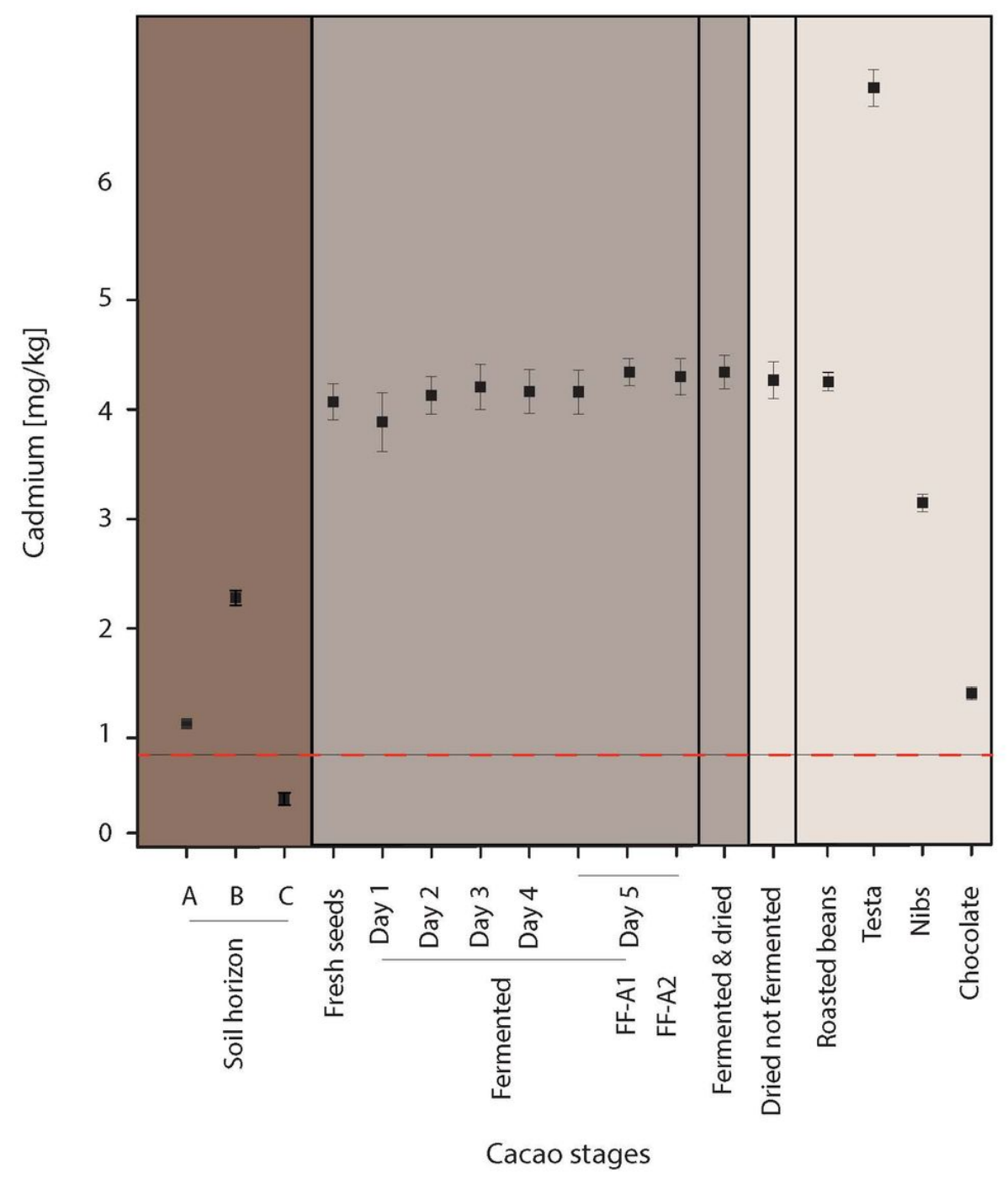

Figure 2

Dynamics of Cd content from soils to chocolate according to the transformation stage. Vertical bars denote standard deviation values. 


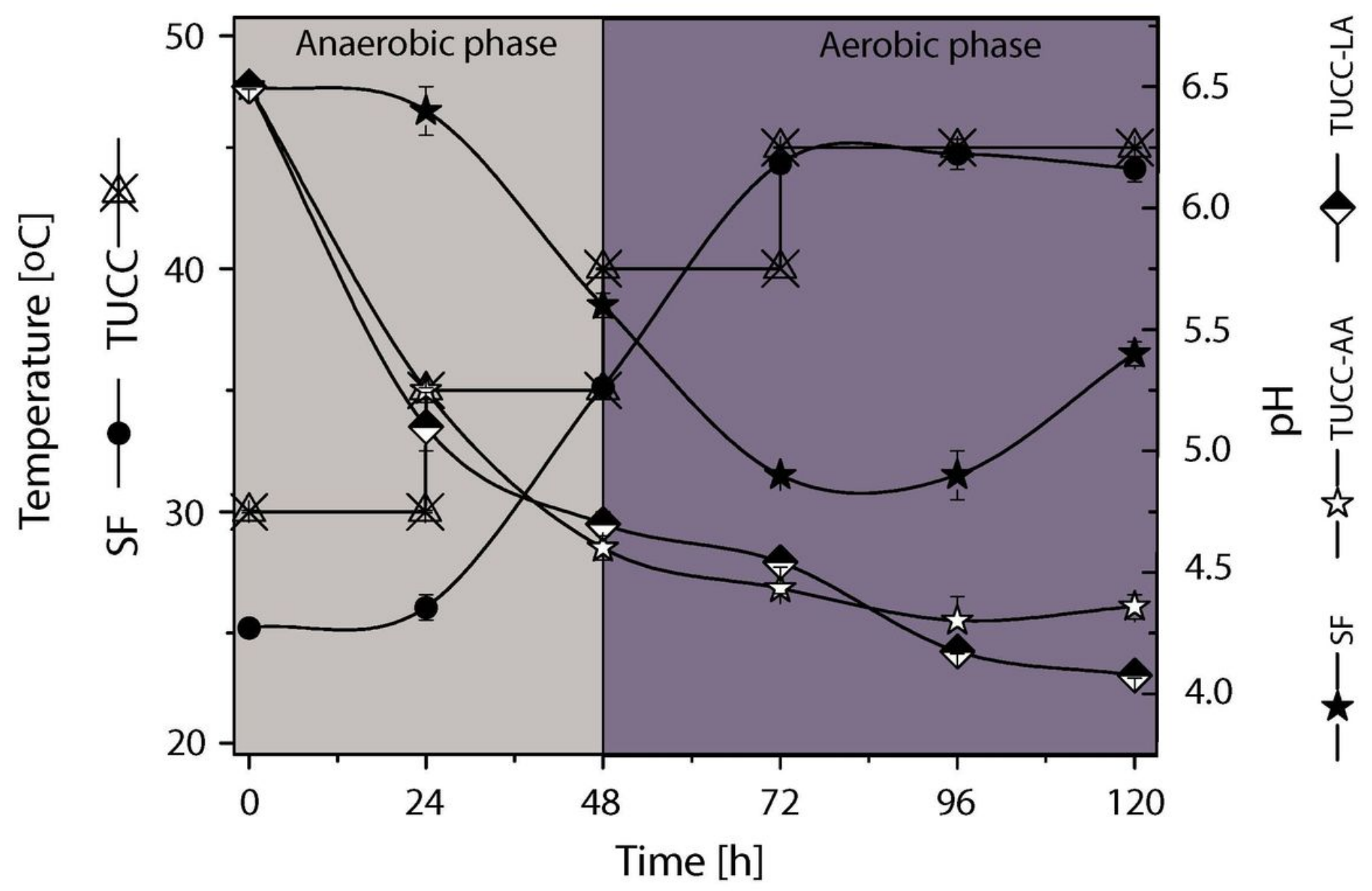

Figure 3

$\mathrm{pH}$ and temperature fluxes of cacao seeds when using spontaneous (SF) and 'transformation under controlled conditions' (TUCC) treatments, at steady-state conditions. Vertical bars denote standard deviation values.

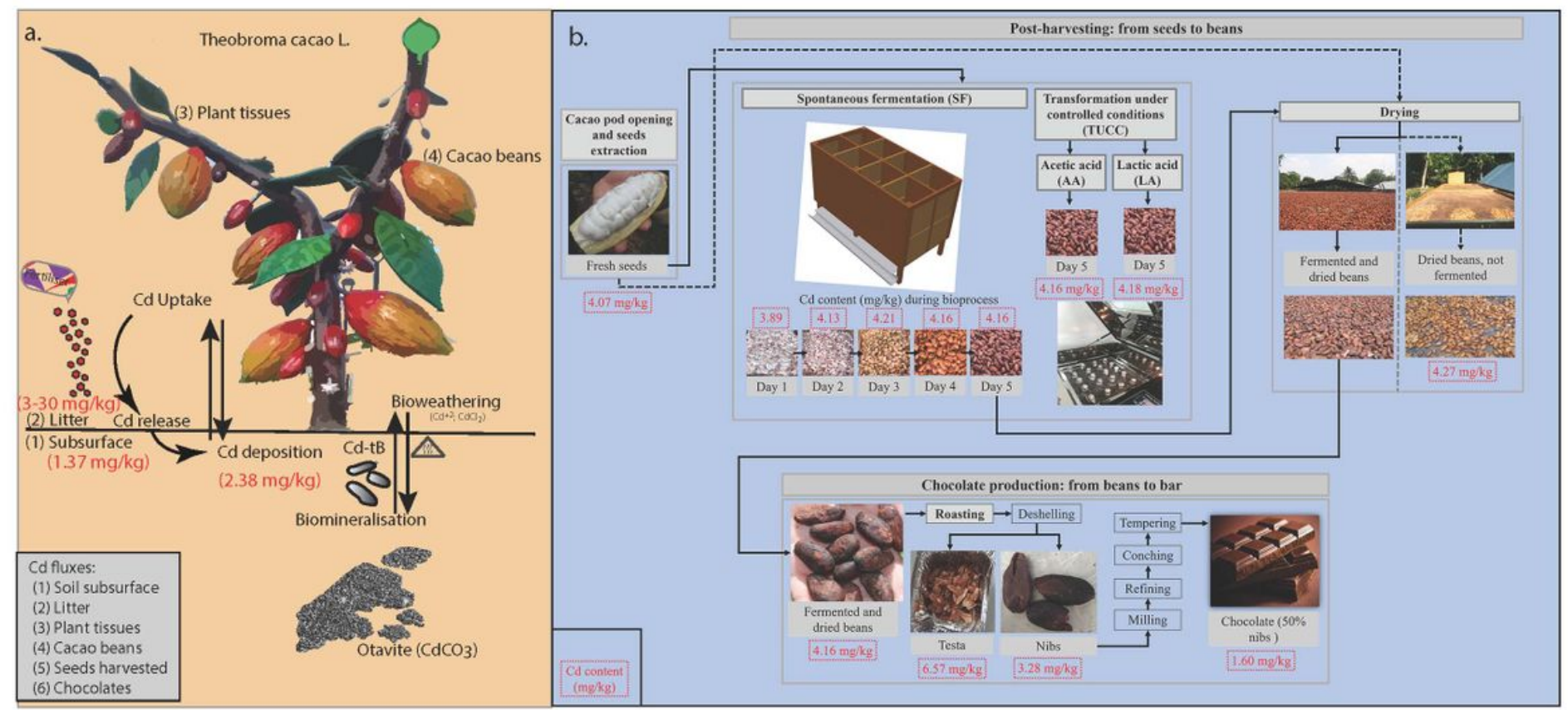


The Cd flux from a. cacao soils to b. post-harvest and chocolate production, seen as a whole system.

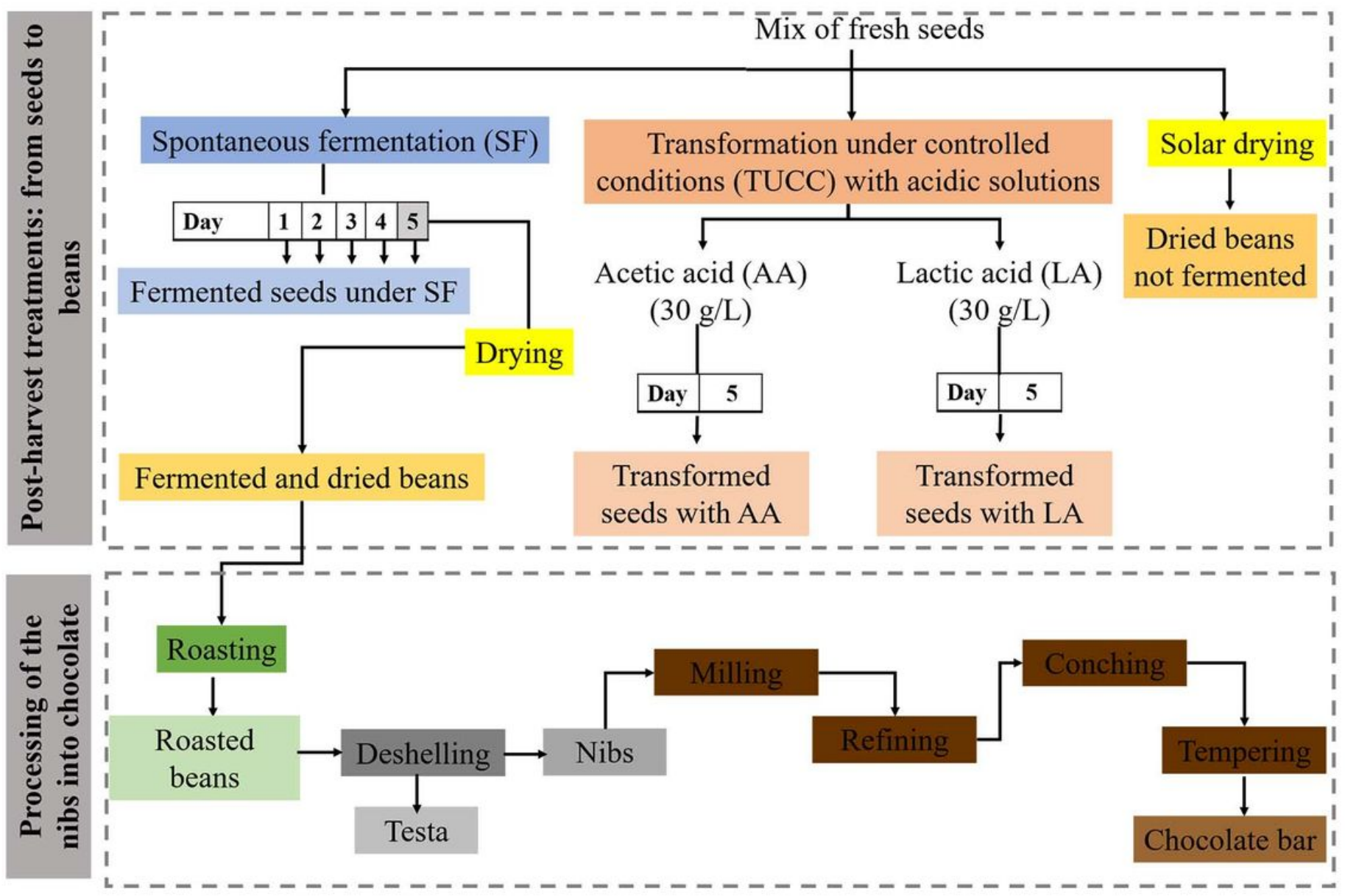

Figure 5

Schematic of the treatments used for the transformation of seeds to cocoa beans and chocolate. Postharvest treatments are highlighted with dark colours, while samples derived for cadmium analysis were drawn with opaque colours. 

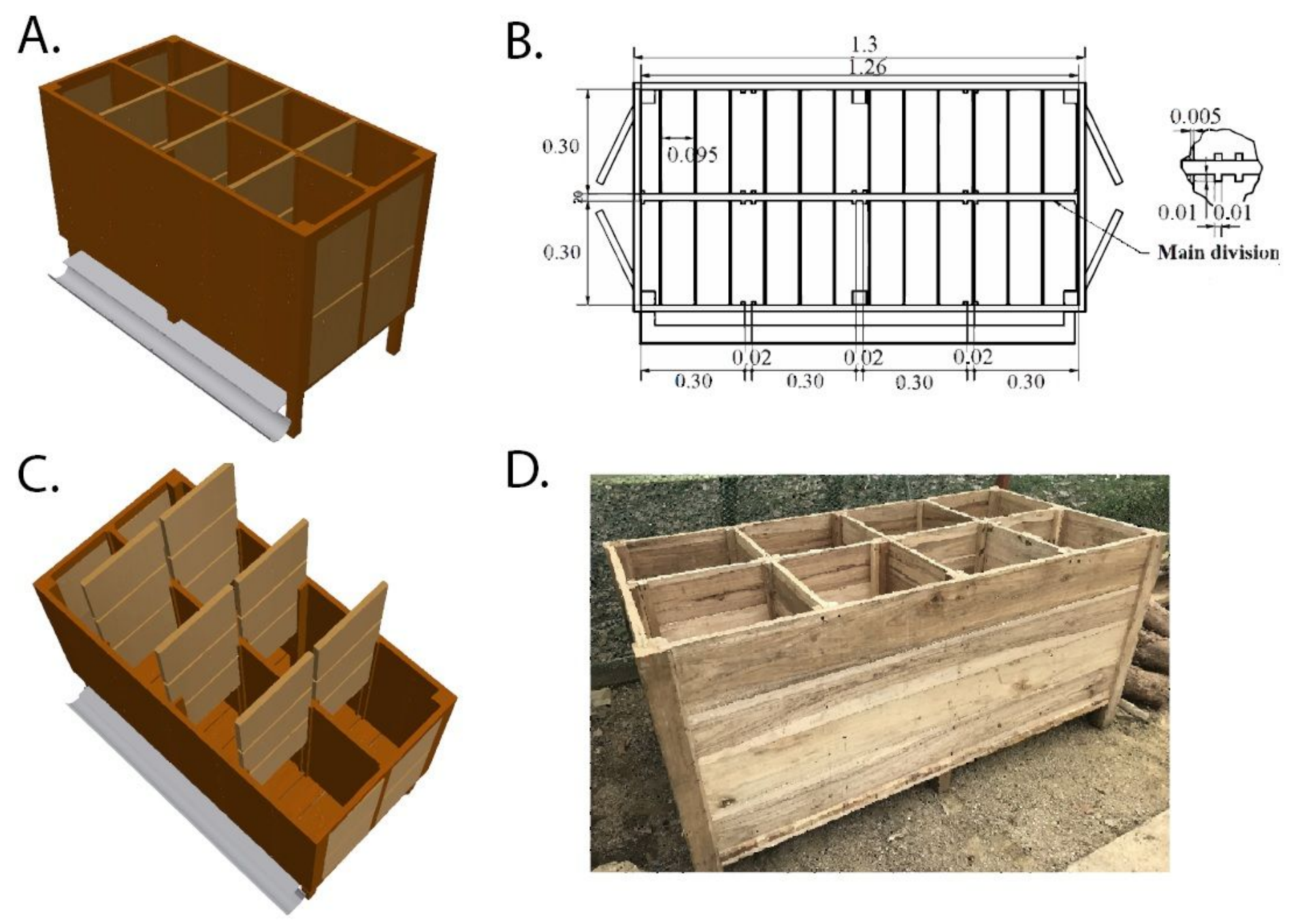

D.

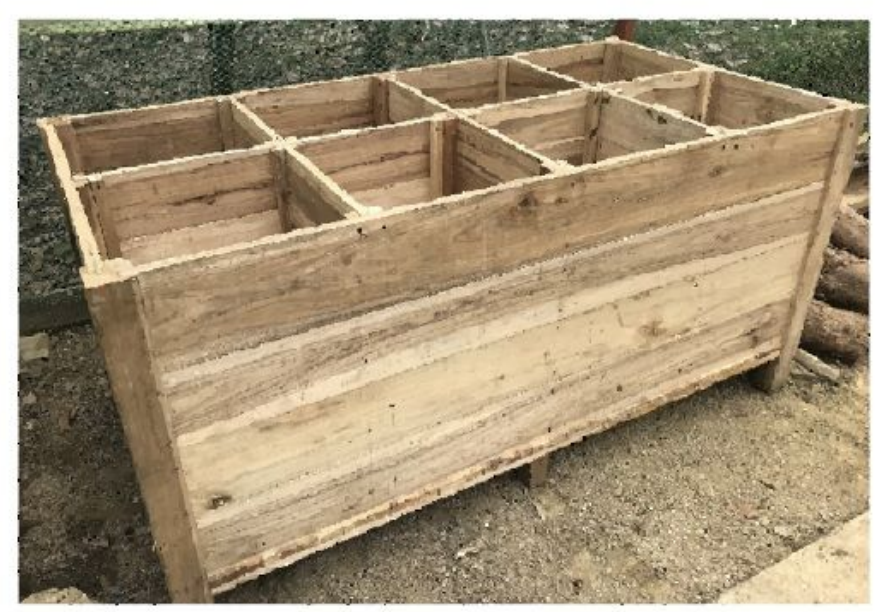

Figure 6

Seed fermentation system used for spontaneous fermentation (SF) and Cd assessments. a. Front view. b. Design and measurements. c. Top view. d. Side view. Source: the authors.

\section{Supplementary Files}

This is a list of supplementary files associated with this preprint. Click to download.

- Supplementarytablefigures.pdf 